\title{
Prophylaxis with resin in wood ants
}

\author{
GREGOIRE CASTELLA, MICHEL CHAPUISAT \& PHILIPPE CHRISTE \\ Department of Ecology and Evolution, Biophore, University of Lausanne \\ (Received 9 July 2007; initial acceptance 1 October 2007; \\ final acceptance 17 October 2007; published online 2 January 2008; MS. number: 9449)
}

\begin{abstract}
Animals may use plant compounds to defend themselves against parasites. Wood ants, Formica paralugubris, incorporate pieces of solidified conifer resin into their nests. This behaviour inhibits the growth of bacteria and fungi in nest material and protects the ants against some detrimental microorganisms. Here, we studied the resin-collecting behaviour of ants under field and laboratory conditions. First, we focused on an important assumption of the self-medication hypothesis, which is that the animals deliberately choose the active plant material. In field cafeteria tests, the ants indeed showed a strong preference for resin over twigs and stones, which are building materials commonly encountered in their environment. We detected seasonal variation in the choice of ants: the preference for resin over twigs was more pronounced in spring than in summer, whereas in autumn the ants collected twigs and resin at equal rates. Second, we found almost similar seasonal patterns when comparing the collecting rates of pieces of wood that had been impregnated with turpentine (a distillate of oleoresin) and untreated pieces of wood, which reveals that the preference for resin is based on odour cues. Third, we tested whether the collection of resin is prophylactic or therapeutic. We found that the relative collection rate of resin versus stones did not depend on an experimental infection with the entomopathogenic fungus Metarhizium anisopliae in laboratory colonies. Together, these results show that the ants deliberately choose the resin and suggest that resin collection is prophylactic rather than therapeutic.
\end{abstract}

(C) 2007 The Association for the Study of Animal Behaviour. Published by Elsevier Ltd. All rights reserved.

Keywords: antiparasite behaviour; Formica paralugubris; medication; olfaction; prophylaxis; resin; wood ant

To fend off the detrimental effects of parasitism, hosts have evolved diverse behavioural defences (Hart 1990), such as detecting and avoiding parasites (Christe et al. 1994), removing diseased individuals (Arathi et al. 2006) or grooming (Mooring et al. 2004). Some animals may also exploit the antipathogenic potential of substances produced by other species either to prevent (prophylactic) or to cure (therapeutic) parasitic infection (Lozano 1998). Such defence mechanisms, that is, defence against parasites by one species using substances produced by another, are usually described as self-medication behaviours (Clayton \& Wolfe 1993). There has been considerable debate over what constitutes true adaptive medication (Sapolsky 1994). Clayton \& Wolfe (1993) have proposed that three criteria should be fulfilled: (1) the medicinal substance must have a detrimental effect on one or more parasites affecting the host, (2) it must have

Correspondence: G. Castella, Department of Ecology and Evolution, Biophore, University of Lausanne, Lausanne CH-1015, Switzerland (email: gregoire.castella@unil.ch). a positive effect on the host fitness in the presence of parasites and (3) the host must deliberately choose the plant containing the medicinal substance.

Most examples of self-medication concern the exploitation of plant secondary metabolites by vertebrates (Rodriguez \& Wrangham 1993). Plant metabolites display a wide range of biological activities (Cowan 1999) and serve to deter phytophages, microbial predators or parasites (Hadacek 2002). Although the differentiation between nutritional and medicinal values of food items remains generally problematic (Sapolsky 1994), one of the most convincing examples of animal medication is the ingestion by chimpanzees, Pan troglodytes, of some particular plant species to cure helminth infections (Wrangham 1995; Huffman 2001).

Incorporating green plants into the nest material may be another way to medicate (Clayton \& Wolfe 1993). Such behaviours have been reported in several bird species (Wimberger 1984). Whereas many studies found a negative effect of plant greenery on bird parasites (Clark \& Mason 1985; Gwinner \& Berger 2005; Shutler \& Campbell 2007), most failed to show any direct fitness benefit for 
the birds (Fauth et al. 1991; Gwinner et al. 2000; Gwinner \& Berger 2006).

Incorporating plant material into the nest as a way to keep pathogens at bay is not restricted to vertebrates. As noticed by naturalists since the 18th century (Réaumur 1928), workers of the wood ants, Formica paralugubris, collect solidified conifer resin that they incorporate into their nests. As resin contains several antimicrobial compounds (Cowan 1999; Phillips \& Croteau 1999) and protects conifers against invading bacteria and fungi (Martin et al. 2002), its incorporation into the nest material may be a form of medication. Two recent studies gave strong support to this hypothesis. First, the presence of resin decreased the density of bacteria and fungi in nest material and inhibited the growth of potentially pathogenic species in vitro (Christe et al. 2003). Second, adult workers and larvae experimentally infected with the bacteria Pseudomonas fluorescens and larvae challenged with the fungal entomopathogen Metarhizium anisopliae survived better in presence than in absence of resin (Chapuisat et al. 2007). These two studies satisfy the first two criteria for adaptive medication. However, the third criterion, that resin should be deliberately chosen, remains to be investigated.

The first aim of this study was to examine whether the ants actively choose the plant material containing the active substance, pieces of resin in our case. To answer this question, we performed cafeteria tests in the field and in the laboratory. We investigated whether workers preferentially collect resin over other building materials present in their environment. We also examined whether the potential preference of workers for resin showed seasonal variation.

The second aim was to determine whether wood ants rely on olfactory cues to discriminate resin from other material. We compared the collecting rate of pieces of wood impregnated with resin-specific volatile compounds (turpentine) with the collecting rate of untreated pieces of wood. We also examined whether this choice showed seasonal variation.

The third aim was to investigate whether resin collection is prophylactic or therapeutic. We infected laboratory colonies with a fungal entomopathogen, M. anisopliae, and examined the effect on resin collection. Specifically, we compared the relative preference of infected and control colonies for resin and stones. If resin collection is prophylactic, workers from infected and control colonies should have a similar preference for resin, whereas the preference for resin should increase in infected colonies if resin collection is a therapeutic behaviour.

\section{METHODS}

\section{Study Population}

The $F$. paralugubris study population is located near the Chalet à Roch $\left(46^{\circ} 32^{\prime} 32^{\prime \prime} \mathrm{N}, 06^{\circ} 11^{\prime} 08^{\prime \prime} \mathrm{E}\right)$ in the Swiss Jura mountains and consists of hundreds of large mounds forming a supercolony (Chapuisat et al. 1997). The density of nests is very high, each mound contains many related queens and neighbouring mounds are interconnected by trails (Chapuisat \& Keller 1999).

\section{Cafeteria Tests in the Field}

\section{Preference experiment}

A first set of cafeteria tests was performed in the field to examine whether workers prefer resin over twigs and stones. The cafeteria tests took place on trails with a dense traffic of workers. The tests were conducted during the morning, in sunny weather, and lasted usually for $6 \mathrm{~h}$. Some of the tests (5\%) lasted for only $4 \mathrm{~h}$ because they had to be terminated before the start of mountain rain showers. In all tests on any given day, resin, twigs and stones were presented together for the same duration.

Three plastic trays were randomly placed in an area of $0.04 \mathrm{~m}^{2}$ previously cleared of branches and stones. On each tray, a mean of $1.45 \pm 0.23 \mathrm{~g}$ resin, $1.52 \pm 0.32 \mathrm{~g}$ stones or $1.42 \pm 0.19 \mathrm{~g}$ twigs were deposited, representing ca. 60 pieces for each material. The area was then monitored for $1 \mathrm{~min}$ to ensure that workers visited all three trays. If one or more trays were not visited during this period, its position was changed to facilitate workers' visit. At the end of the test, the material remaining in each tray was weighed. Twenty-eight trails were tested in spring (April 2007), 45 in summer (July 2006) and 23 in autumn (October 2006), resulting in 96 replicates. Each trail was connected to a different nest and was tested only once per season.

\section{Odour cues experiment}

A second set of cafeteria tests was performed to investigate whether wood ant workers distinguished resin from other material by means of olfactory cues. We compared the collecting rates of pieces of wood impregnated with turpentine (a distillate of conifer resin; ARIES SA, Switzerland) and untreated pieces of wood. In a glass container, we mixed turpentine with pieces of wood at a 1:500 weight ratio and left them to impregnate for 2 weeks. The pieces of untreated wood were put into a glass container without turpentine. Cafeteria tests consisted of two trays filled with $1.65 \pm 0.52$ or $1.68 \pm 0.58 \mathrm{~g}$ turpentine-treated or untreated wood, respectively, corresponding to ca. 150 pieces, placed on an ant trail. Twenty-seven trails were tested in spring (April 2007), 29 in summer (July 2006) and 35 in autumn (October 2006), resulting in 91 replicates. Again, only independent trails connected to different nests were tested in each season.

\section{Infection Experiment}

In July 2005, we collected 3 litres of nest material and workers from each of 15 randomly chosen nests (total 45 litres). Nest material was sampled from within the upper parts of the mounds and consisted of twigs and needles. When present, queens and pupae were also collected. Nest material and workers from all colonies were mixed together, taking advantage of the lack of aggression between individuals in this population (Holzer et al. 2006). 
All pieces of resin were removed from nest material with soft forceps.

Experimental units were composed of a large plastic container harbouring the nest and connected to a smaller arena by a transparent plastic pipe $(25 \mathrm{~cm}$, diameter $1.5 \mathrm{~cm}$ ). All containers were side-coated with fluon to prevent ants from escaping. The homogenous stock of workers and nest material was split into 30 parts and allocated to 30 experimental units. Each experimental unit thus consisted of approximately 1.4 litres of nest material and 800 workers. Two queens, 25 pupae, one larva and 12 eggs were also added to each experimental unit. Solid food (a mixture of water, honey, agar and egg) and a tube filled with distilled water were provided in the foraging arena. The units were left for 4 days so that the ants could get used to the experimental set-up and construct their nest. Experimental units were kept at $25^{\circ} \mathrm{C}$ with daily vaporization of sterile water to maintain high humidity.

The fungus $M$. anisopliae is a virulent pathogen of wood ants (Chapuisat et al. 2007). We used here a wild strain that we isolated from a soil sample in the upper Rhône Valley in Switzerland (A. Reber et al., unpublished data) and cultured on a nutritive medium (malt extract Agar; Oxoid) for 5 days. Spores were harvested and suspended in a sterile Tween $20(0.05 \%)$ solution $\left(1.3 \times 10^{8}\right.$ spores/ $\mathrm{ml}$ ). One half of the colonies were infected with $3 \mathrm{ml}$ of the spore solution and the other half received $3 \mathrm{ml}$ of a Tween $20(0.05 \%)$ solution. These were deposited on a filter paper $\left(64 \mathrm{~cm}^{2}\right)$ in the nest area. Later, the infected group received $2 \mathrm{ml}$ of spore solution every 2 days during 8 days whereas the control group received $2 \mathrm{ml}$ of Tween 20 solution. This infection mode was efficient in an earlier study (Chapuisat et al. 2007).

At the beginning of the experiment, $0.5 \mathrm{~g}$ resin and $0.5 \mathrm{~g}$ stones, corresponding to ca. 25 pieces, were placed on a single plastic tray in the foraging area. After $6 \mathrm{~h}$, the resin and stones remaining in the foraging area were weighed and both were replenished up to $0.5 \mathrm{~g}$. This procedure was repeated every $24 \mathrm{~h}$ for 20 days.

\section{Statistical Analyses}

We analysed the data with two-way ANOVA mixed models. Material type (resin, twigs or stones and turpentine-impregnated or untreated pieces of wood), season (spring, summer or autumn) and infection status (infected or control) were used as fixed factors, whereas replicates were used as random factors. The models were fitted using the REML method. Differences between groups were tested with paired Student's $t$ tests. All statistical analyses were performed with JMP 6.0 (SAS Institute Inc., Cary, NC, U.S.A.).

\section{RESULTS}

\section{Preference Experiments}

Wood ant workers preferred to collect some material over others in field cafeteria tests (Table 1). Overall, workers showed a strong preference for resin over twigs
Table 1. Cafeteria tests with resin, twigs and stones (two-way mixed model on the mass collected)

\begin{tabular}{|lcrrr|}
\hline & $d f$ num & $d f$ den & $F$ & \multicolumn{1}{c|}{$P$} \\
\hline Material type & 2 & 186 & 43.79 & $<0.0001$ \\
Season & 2 & 93 & 8.90 & 0.0003 \\
Material type*season & 4 & 186 & 7.31 & $<0.0001$ \\
\hline
\end{tabular}

(mean mass \pm SE: resin $=0.60 \pm 0.04 \mathrm{~g} ;$ twigs $=0.39 \pm$ $0.03 \mathrm{~g} ; t=-4.40, d f=95, P<0.001)$ which in turn were preferred over stones (mean mass \pm SE: stone $=0.21 \pm$ $0.02 \mathrm{~g} ; t=5.67, d f=95, P<0.001)$.

This preference for resin depended on the season as shown by the highly significant interaction between material type and season (Table 1 ). In spring, workers preferred pieces of resin over twigs or stones (Fig. 1; resin versus stones: $t=5.70, d f=27, P<0.001$; resin versus twigs: $t=5.84, d f=27, P<0.001$; stones versus twigs: $t=1.43$, $d f=27, P=0.16)$. In summer, workers collected more resin than twigs and more twigs than stones (Fig. 1; resin versus stones: $t=6.89, d f=44, P<0.001$; resin versus twigs: $t=3.53, d f=44, P=0.001$; stones versus twigs: $t=-4.01, d f=44, P<0.001)$. In autumn, workers preferentially collected twigs and resin over stones (Fig. 1; resin versus stones: $t=3.75, d f=22, P=0.001$; resin versus twigs: $t=-1.37, d f=22, P=0.18$; stones versus twigs: $t=-6.97, d f=22, P<0.001)$.

\section{Odour Cues Experiment}

There was a seasonal variation in the preference for turpentine-impregnated versus untreated pieces of wood, as shown by the highly significant interaction between material type and season (Table 2 ). In spring, workers preferentially collected pieces of wood impregnated with turpentine ( $t=3.83, d f=26, P<0.001$; Fig. 2$)$. In summer, workers had no significant preference $(t=0.78, d f=28$, $P=0.44$; Fig. 2). In autumn, workers preferentially collected untreated pieces of wood $(t=-6.44, d f=34$, $P<0.001$; Fig. 2).

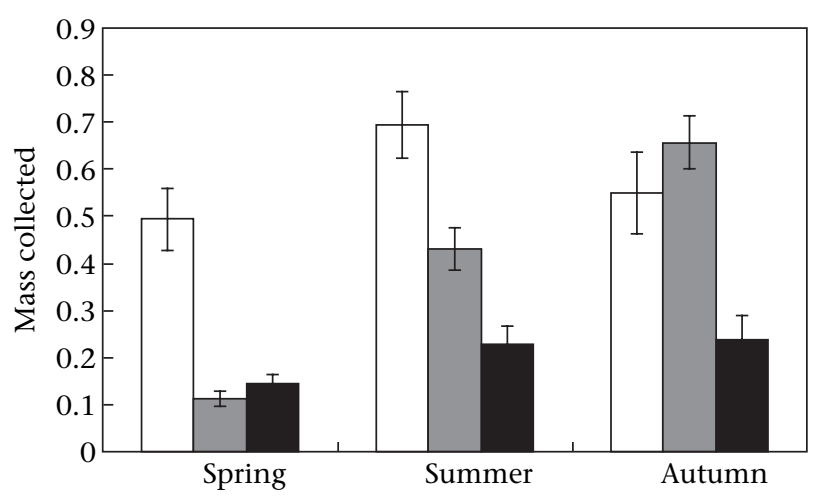

Figure 1. Mean \pm SE mass in g of resin (white bar), twigs (grey bar) and stones (black bar) collected by workers in cafeteria tests, for each season. 
Table 2. Cafeteria tests with turpentine-impregnated and untreated pieces of wood (two-way mixed model on the mass collected)

\begin{tabular}{|lcccc|}
\hline & $d f$ num & $d f$ den & $F$ & $P$ \\
\hline Odour cues & 1 & 88 & 10.26 & 0.002 \\
Season & 2 & 88 & 16.09 & $<0.0001$ \\
Odour cues*season & 2 & 88 & 38.27 & $<0.0001$ \\
\hline
\end{tabular}

\section{Infection Experiment}

Wood ants in laboratory colonies collected a greater amount of resin than stones in both the infected and the control groups (Table 3, Fig. 3). However, colonies infected with $M$. anisopliae gathered significantly less material than colonies from the control group (Table 3, Fig. 3). The relative proportion of resin and stone collected was similar and close to $80 \%$ in both groups, indicating that the experimental infection did not significantly influence the preference for resin (Table 3, Fig. 3).

\section{DISCUSSION}

Wood ants show a strong preference for conifer resin over other building materials under both field and laboratory conditions. This active choice and preference for resin explains the huge quantities of solidified conifer resin found in some wood ant mounds in various geographical areas (up to $20 \mathrm{~kg}$ per mound; Réaumur 1928; Lenoir et al. 1999; Christe et al. 2003).

The demonstration of an active choice for conifer resin by wood ants fulfils an important criterion for adaptive medication (Clayton \& Wolfe 1993). Resin inhibits bacteria and fungi (Christe et al. 2003), increases the survival of ants exposed to pathogens (Chapuisat et al. 2007) and is deliberately collected by wood ant workers (this study). These results are fully consistent with the hypothesis that collecting resin has evolved to fight pathogens, without excluding the possibility that resin has other functions.

The proportion of resin and twigs collected by workers showed seasonal variation. Whereas in spring and summer, workers strongly preferred to collect resin over other

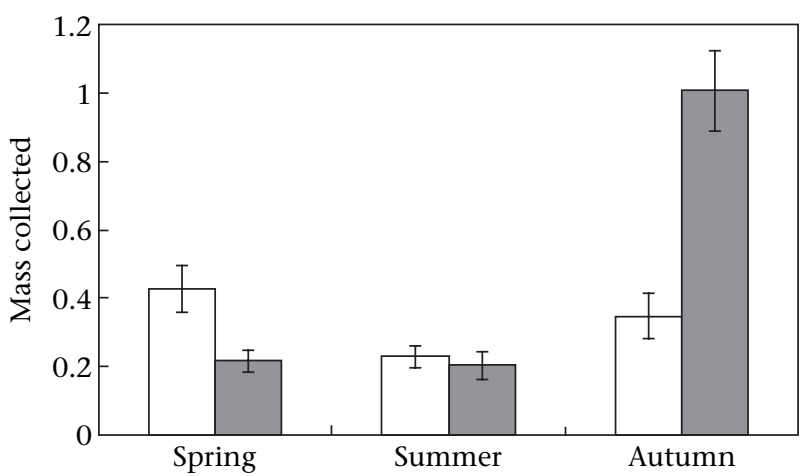

Figure 2. Mean \pm SE mass in $\mathrm{g}$ of turpentine-impregnated wood (white bar), and untreated wood (grey bar) collected by workers in cafeteria tests, for each season.
Table 3. Effect of experimental infection on the relative rate of resin and stone collection (two-way mixed model on the mass collected during 20 days)

\begin{tabular}{|lcccc|}
\hline & $d f$ num $d f$ den & $F$ & $P$ \\
\hline Material type & 1 & 28 & 62.67 & $<0.0001$ \\
Infection status & 1 & 28 & 4.16 & 0.05 \\
Material type*infection status & 2 & 28 & 1.02 & 0.32 \\
\hline
\end{tabular}

material types, this was not the case in autumn. Workers thus bring proportionally more resin and fewer twigs to their colonies during spring and summer than during autumn. This seasonal pattern might be explained by an increased need for twigs in autumn, for instance to prepare the nest for the harsh conditions of winter. Alternatively, it may be due to variation in the costs imposed by parasites throughout the year. Parasites often time their reproduction to that of their hosts (Christe et al. 2000). As the brood is produced and reared in spring and summer, large amounts of resin might help the larvae to better resist parasites (Chapuisat et al. 2007). Such seasonal variability has been suggested in other animal medication studies. Huffman et al. (1997) reported a seasonal change in medicinal plant intake in chimpanzees and Clark \& Smeraski (1990) suggested that the seasonal shift in sensibility to plant odours observed in starlings might be related to medication via incorporation of green plants to the nest.

Our results suggest that wood ants rely on odour cues to distinguish resin from other material in their environment. Specifically, they strongly discriminate between turpentine-impregnated and untreated pieces of wood. Moreover this preference partially reflects the preference for resin over the seasons. Turpentine is extracted from resin and contains resin-specific volatile compounds, such as monoterpenes and sesquiterpenes. Such chemicals often have both antimicrobial activity and strong odours. This association probably favours the use of olfactory cues to detect medicinal plants (Hart 2005), as suggested for blue tits (Petit et al. 2002).

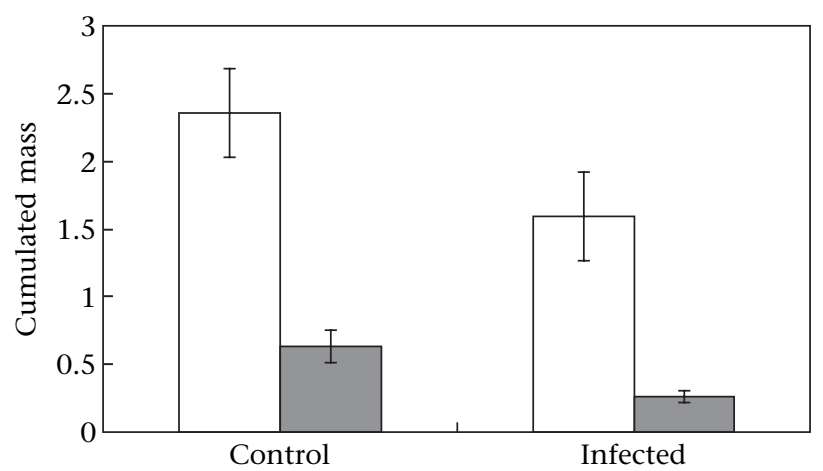

Figure 3. Mean \pm SE mass of resin (white bars) and stone (black bars) collected by workers in the infected and control groups. The masses of both material types (resin and stone) are summed over 20 days. 
The experimental infection with $M$. anisopliae lowered the collecting activity of workers but did not affect the strength of the preference for resin. Resin collection by wood ants thus appears to be a prophylactic behaviour rather than a therapeutic response induced by a pathogen. It is possible that relying on seasonal cues to prophylactically modulate resin intake is more efficient than responding to an infection, particularly if the pressure of parasites varies predictably. More generally, the therapeutic use of medicinal plants suggested in mammals (Huffman 2003; Villalba et al. 2006) may require complex learning abilities (Huffman \& Hirata 2004) and might therefore be less likely to evolve in insects. It should also be noted that, because we tested only one pathogen species, we cannot exclude the possibility that other pathogens might induce a therapeutic response.

Wood ants are not the only insects that use tree resin in original ways. Honeybees, Apis mellifera, seal their hives and encapsulate parasitic beetles with propolis, a resinous substance that has antibacterial properties (Burdock 1998; Neumann et al. 2001), bark beetles, Ips paraconfusus, produce an aggregation pheromone from an $\alpha$-pinene precursor (Renwick et al. 1976) and larvae of pine sawflies, Neodiprion sertifer, repel predators by regurgitating a mixture of terpenes extracted from resin (Eisner et al. 1974). The 'recycling' of plant secondary metabolites by animals might thus be a widespread phenomenon which takes advantage of active chemicals without having to evolve and maintain costly metabolic pathways.

\section{Acknowledgments}

We thank Christophe Hug for help in the field, Jonathan Yearsley and two anonymous referees for their useful comments on the manuscript and the Centre de Conservation de la Faune of the canton de Vaud for permission to collect ants. This research was supported by Grants 3100A0-104118 and 3100AO-108263 from the Swiss National Science Foundation.

\section{References}

Arathi, H. S., Ho, G. \& Spivak, M. 2006. Inefficient task partitioning among nonhygienic honeybees, Apis mellifera L., and implications for disease transmission. Animal Behaviour, 72, 431-438.

Burdock, G. A. 1998. Review of the biological properties and toxicity of bee propolis (propolis). Food and Chemical Toxicology, 36, 347363.

Chapuisat, M. \& Keller, L. 1999. Extended family structure in the ant Formica paralugubris: the role of the breeding system. Behavioral Ecology and Sociobiology, 46, 405-412.

Chapuisat, M., Goudet, J. \& Keller, L. 1997. Microsatellites reveal high population viscosity and limited dispersal in the ant Formica paralugubris. Evolution, 51, 475-482.

Chapuisat, M., Oppliger, A., Magliano, P. \& Christe, P. 2007. Wood ants use resin to protect themselves against pathogens. Proceedings of the Royal Society of London, Series B, 274, 2013-2017.

Christe, P., Oppliger, A. \& Richner, H. 1994. Ectoparasite affects choice and use of roost sites in the great tit, Parus major. Animal Behaviour, 47, 895-898.
Christe, P., Arlettaz, R. \& Vogel, P. 2000. Variation in intensity of a parasitic mite (Spinturnix myoti) in relation to the reproductive cycle and immunocompetence of its bat host (Myotis myotis). Ecology Letters, 3, 207-212.

Christe, P., Oppliger, A., Bancalà, F., Castella, G. \& Chapuisat, M. 2003. Evidence for collective medication in ants. Ecology Letters, 6 , 19-22.

Clark, L. \& Mason, J. R. 1985. Use of nest material as insecticidal and anti-pathogenic agents by the European starling. Oecologia, 67, 169-176.

Clark, L. \& Smeraski, C. A. 1990. Seasonal shifts in odor acuity by starlings. Journal of Experimental Zoology, 255, 22-29.

Clayton, D. H. \& Wolfe, N. D. 1993. The adaptive significance of self-medication. Trends in Ecology \& Evolution, 8, 60-63.

Cowan, M. M. 1999. Plant products as antimicrobial agents. Clinical Microbiology Reviews, 12, 564-582.

Eisner, T., Johnesse, J., Carrel, J., Hendry, L. B. \& Meinwald, J. 1974. Defensive use by an insect of a plant resin. Science, 184, 996-999.

Fauth, P. T., Krementz, D. G. \& Hines, J. E. 1991. Ectoparasitism and the role of green nesting material in the European starling. Oecologia, 88, 22-29.

Gwinner, H. \& Berger, S. 2005. European starlings: nestling condition, parasites and green nest material during the breeding season. Journal of Ornithology, 146, 365-371.

Gwinner, H. \& Berger, S. 2006. Parasite defence in birds: the role of volatiles. Acta Zoologica Sinica, 52, 280-283.

Gwinner, H., Oltrogge, M., Trost, L. \& Nienaber, U. 2000. Green plants in starling nests: effects on nestlings. Animal Behaviour, 59, 301-309.

Hadacek, F. 2002. Secondary metabolites as plant traits: current assessment and future perspectives. Critical Reviews in Plant Sciences, 21, 273-322.

Hart, B. L. 1990. Behavioral adaptations to pathogens and parasites: 5 strategies. Neuroscience and Biobehavioral Reviews, 14, 273-294.

Hart, B. L. 2005. The evolution of herbal medicine: behavioural perspectives. Animal Behaviour, 70, 975-989.

Holzer, B., Chapuisat, M., Kremer, N., Finet, C. \& Keller, L. 2006. Unicoloniality, recognition and genetic differentiation in a native Formica ant. Journal of Evolutionary Biology, 19, 2031-2039.

Huffman, M. A. 2001. Self-medicative behavior in the African great apes: an evolutionary perspective into the origins of human traditional medicine. Bioscience, 51, 651-661.

Huffman, M. A. 2003. Animal self-medication and ethno-medicine: exploration and exploitation of the medicinal properties of plants. Proceedings of the Nutrition Society, 62, 371-381.

Huffman, M. A. \& Hirata, S. 2004. An experimental study of leaf swallowing in captive chimpanzees: insights into the origin of a self-medicative behavior and the role of social learning. Primates, 45, 113-118.

Huffman, M. A., Gotoh, S., Turner, L. A., Hamai, M. \& Yoshida, K. 1997. Seasonal trends in intestinal nematode infection and medicinal plant use among chimpanzees in the Mahale Mountains, Tanzania. Primates, 38, 111-125.

Lenoir, L., Bengtsson, J. \& Persson, T. 1999. Effects of coniferous resin on fungal biomass and mineralisation processes in wood ant nest materials. Biology and Fertility of Soils, 30, 251-257.

Lozano, G. A. 1998. Parasitic stress and self-medication in wild animals. Advances in the Study of Behavior, 27, 291-317.

Martin, D., Tholl, D., Gershenzon, J. \& Bohlmann, J. 2002. Methyl jasmonate induces traumatic resin ducts, terpenoid resin biosynthesis, and terpenoid accumulation in developing xylem of Norway spruce stems. Plant Physiology, 129, 1003-1018. 
Mooring, M. S., Blumstein, D. T. \& Stoner, C. J. 2004. The evolution of parasite-defence grooming in ungulates. Biological Journal of the Linnean Society, 81, 17-37.

Neumann, P., Pirk, C. W. W., Hepburn, H. R., Solbrig, A. J., Ratnieks, F. L. W., Elzen, P. J. \& Baxter, J. R. 2001. Social encapsulation of beetle parasites by Cape honeybee colonies (Apis mellifera capensis Esch.). Naturwissenschaften, 88, 214-216.

Petit, C., Hossaert-McKey, M., Perret, P., Blondel, J. \& Lambrechts, M. M. 2002. Blue tits use selected plants and olfaction to maintain an aromatic environment for nestlings. Ecology Letters, 5, 585-589.

Phillips, M. A. \& Croteau, R. B. 1999. Resin-based defenses in conifers. Trends in Plant Science, 4, 184-190.

de Réaumur, R. A. F. 1928. Histoire des Fourmis (1742-1743). Paris: Paul Lechevallier.

Renwick, J. A. A., Hughes, P. R. \& Krull, I. S. 1976. Selective production of cis-verbenol and trans-verbenol from (-)- and (+)alpha-pinene by a bark beetle. Science, 191, 199-201.
Rodriguez, E. \& Wrangham, R. W. 1993. Zoopharmacognosy: the use of medicinal plants by animals. In: Phytochemical Potential of Tropical Plants (Ed. by K. R. Downum), pp. 89-105. New York: Plenum.

Sapolsky, R. M. 1994. Fallible instinct: a dose of skepticism about the medicinal knowledge of animals. Sciences-New York, 34, 13-15.

Shutler, D. \& Campbell, A. A. 2007. Experimental addition of greenery reduces flea loads in nests of a non-greenery using species, the tree swallow Tachycineta bicolor. Journal of Avian Biology, 38, 7-12.

Villalba, J. J., Provenza, F. D. \& Shaw, R. 2006. Sheep self-medicate when challenged with illness-inducing foods. Animal Behaviour, 71, 1131-1139.

Wimberger, P. H. 1984. The use of green plant-material in bird nests to avoid ectoparasites. Auk, 101, 615-618.

Wrangham, R. W. 1995. Relationship of chimpanzee leaf-swallowing to a tapeworm infection. American Journal of Primatology, 37, 297-303. 